Article

\title{
Investigation of L-Tryptophan Electrochemical Oxidation with a Graphene-Modified Electrode
}

\author{
Florina Pogacean, Codruta Varodi, Maria Coros, Irina Kacso, Teodora Radu, Bogdan Ionut Cozar, Valentin Mirel \\ and Stela Pruneanu * (D)
}

Citation: Pogacean, F.; Varodi, C.; Coros, M.; Kacso, I.; Radu, T.; Cozar, B.I.; Mirel, V.; Pruneanu, S. Investigation of L-Tryptophan Electrochemical Oxidation with a Graphene-Modified Electrode. Biosensors 2021, 11, 36. https:// doi.org/10.3390/bios11020036

Received: 12 November 2020

Accepted: 25 January 2021

Published: 28 January 2021

Publisher's Note: MDPI stays neutral with regard to jurisdictional claims in published maps and institutional affiliations.

Copyright: (c) 2021 by the authors. Licensee MDPI, Basel, Switzerland. This article is an open access article distributed under the terms and conditions of the Creative Commons Attribution (CC BY) license (https:/ / creativecommons.org/licenses/by/ $4.0 /)$.
National Institute for Research and Development of Isotopic and Molecular Technologies, Donat Street, No. 67-103, 400293 Cluj-Napoca, Romania; florina.pogacean@itim-cj.ro (F.P.); codruta.varodi@itim-cj.ro (C.V.); maria.coros@itim-cj.ro (M.C.); irina.kacso@itim-cj.ro (I.K.); teodora.radu@itim-cj.ro (T.R.); bogdan.cozar@itim-cj.ro (B.I.C.); valentin.mirel@itim-cj.ro (V.M.)

* Correspondence: stela.pruneanu@itim-cj.ro

\begin{abstract}
A graphene sample (EGr) was prepared by electrochemical exfoliation of graphite rods in solution containing $0.05 \mathrm{M}\left(\mathrm{NH}_{4}\right)_{2} \mathrm{SO}_{4}+0.1 \mathrm{M} \mathrm{H}_{3} \mathrm{BO}_{3}+0.05 \mathrm{M} \mathrm{NaCl}$. The exfoliation was performed by applying a constant voltage $(12 \mathrm{~V})$ between the graphite rods, while the temperature was kept constant $\left(18^{\circ} \mathrm{C}\right)$ with a temperature-controlled cryostat. The structural investigation of the graphene sample, performed by X-ray powder diffraction (XRD), revealed that the sample consists of a mixture of few-layer $(69 \%)$, multi-layer graphene $(14 \%)$ and graphene oxide $(17 \%)$. In addition, XPS analysis proved that the sample was triple-doped with heteroatoms such as nitrogen (1.7 at $\%)$, sulfur ( $2.5 \mathrm{at} \%)$, and boron ( 3 at $\%)$. The sample was deposited onto the surface of a clean, glassy carbon electrode (GC) and investigated for the non-enzymatic electrochemical detection of L-tryptophan (TRP). The electrocatalytic properties of the EGr/GC electrode led to a considerable decrease in the oxidation potential from $+0.9 \mathrm{~V}$ (bare GC) to $+0.72 \mathrm{~V}$. In addition, the EGr/GC electrode has higher sensitivity (two times) and a lower detection limit (ten times) in comparison with the bare GC electrode.
\end{abstract}

Keywords: electrochemical exfoliation; doped graphene; heteroatoms; enhanced detection

\section{Introduction}

In the last few years, intensive research has been devoted to the development of analytical methods useful for the detection of biomolecules present in living species. Since various biomolecules coexist in the human body, it is a difficult task to detect them in a single run due to their different physical-chemical properties. The nonenzymatic electrochemical methods may be useful for the detection of important biomolecules (e.g., L-tryptophan, ascorbic acid, dopamine, uric acid) based on the fact that they have different oxidation potentials.

To fulfill the increasing interest in ultrasensitive detection, scientists have developed novel procedures to improve the response of electrochemical sensors by modifying them with various functional materials [1]. Due to its diverse structural, morphological, and chemical properties, graphene has found applications in numerous fields, including sensing material [2]. Nevertheless, pristine graphene tends to agglomerate, causing a loss of performance in the detection process. Therefore, it is necessary to modify graphene in order to diminish this weakness. Doping graphene with nitrogen, boron, sulfur, phosphorus, or combinations of these elements can substantially improve the characteristics of the materials [3]. So far, a large number of reports have confirmed the positive effects of heteroatom doping on the electrochemical property enhancement of graphene [4]. Multiple doping is more efficient in comparison with mono-heteroatom doping since co-doped graphene materials have revealed a range of unique properties due to the synergistic effect of multiple-element doping [5]. Heteroatom doping of graphene can be achieved by the CVD method [6], thermal annealing of graphene oxide (GO) with heteroatom 
precursors [7], plasma [8] and arc-discharge [9] techniques, or solvothermal synthesis [10]. Recently, electrochemical exfoliation of graphite has attracted attention due to its easy, rapid, and environmentally friendly approach to producing high-quality doped graphene [11] Although co-doped carbon materials potentially possess promising properties for various applications, there are only a few reports about graphene that is simultaneously doped with nitrogen, sulfur, and boron [12].

Tryptophan is an essential amino acid for humans [13] and a precursor for the neurotransmitter serotonin or the hormone melatonin [14], important substances in the modulation of several important behaviors and psychological functions such as sleep, emotional state, perception, and circadian rhythm [15]. A significant association between plasma tryptophan concentrations, sleep, and good mental health has been reported [16]. Consequently, a sensitive method for tryptophan determination is very useful. Among the methods used for the determination of tryptophan, chromatographic [17], chemiluminescence [18], capillary electrophoresis [19], and electrochemical techniques [20] were highly sensitive, accurate, and simple to use. Various materials for electrode modification have been employed so far, such as nitrogen-doped graphene nanosheets $/ \mathrm{CuCo}_{2} \mathrm{O}_{4}$ [21], poly(L-methionine)/graphene [22], a flower-like-structured nanocomposite consisting of reduced graphene oxide and $\mathrm{SnO}_{2}$ [23], $\mathrm{Cu}_{2} \mathrm{O}$-nanoparticle-coated reduced graphene oxide [24], polyvinylpyrrolidone-functionalized graphene [25], and 3D nitrogen and sulfur co-doped graphene/integrated polysaccharides [26]. To the best of our knowledge, no study has been published on tryptophan determination using nitrogen-, sulfur-, and boron-doped graphene.

In this work, we report an easy electrochemical method for the synthesis of goodquality triple-doped graphene $(\mathrm{N}, \mathrm{S}, \mathrm{B})$ in aqueous electrolytes containing ammonium sulfate, boric acid, and sodium chloride. Our method has the advantage of short processing time and mild reaction conditions. Incorporating N, S, B into the electrochemically exfoliated graphene sheets showed favorable electrocatalytic activity towards tryptophan detection.

\section{Materials and Methods}

\subsection{Instruments}

An SEM/TEM Hitachi HD2700 instrument (Hitachi, Japan), equipped with a cold field emission gun (CSEG), operated at $200 \mathrm{kV}$, and coupled with a double-cut windowless 100 EDX detector using AZtec Software (Oxford Instruments, Oxford, UK), was used for the morphological characterization of the graphene sample.

The X-ray powder diffraction (XRD) pattern was collected with a Bruker D8 Advance Diffractometer using $\mathrm{CuK}_{\alpha 1}$ radiation $(\lambda=1.5406 \AA)$. Background-corrected patterns were used for the determination of some structural parameters.

The FTIR spectrum measurement $\left(4000-400 \mathrm{~cm}^{-1}\right.$ spectral domain) was obtained with a resolution of $4 \mathrm{~cm}^{-1}$ using a JASCO 6100 FTIR spectrometer (KBr pellet technique). Around $1 \mathrm{mg}$ of graphene was mixed with $\sim 200 \mathrm{mg} \mathrm{KBr}$ and grounded in an agate mortar. The grounded mixture was pressed into a pellet; then, the spectrum was immediately recorded.

The X-ray photoelectron spectroscopy (XPS) technique was employed to investigate the surface chemical composition of the sample. A SPECS spectrometer, equipped with an $\mathrm{Al}$ anode $\mathrm{X}$-ray source and a PHOIBOS 150 2D CCD hemispherical energy analyzer, was used for the measurements. The X-ray source $\left(\mathrm{Al} \mathrm{K} \mathrm{K}_{\alpha}, 1486.6 \mathrm{eV}\right)$ was operated at $200 \mathrm{~W}$. High-resolution X-ray photoelectron spectra for individual elements (C, O, B, S) were recorded by accumulating scans at constant pass energy of 30 and $0.1 \mathrm{eV} / \mathrm{step}$. Data analysis and deconvolutions were performed using CasaXPS software with a GaussianLorentzian product function and a nonlinear Shirley function for background subtraction. Peak shifts due to any apparent charging were calibrated by attributing the energy value of $284.6 \mathrm{eV}$ to the $\mathrm{C} 1 \mathrm{~s}$ peak.

A typical three-electrode cell, coupled with a potentiostat/galvanostat instrument (PGSTAT-302N, Metrohm-Autolab B.V., The Netherlands), was used for the electrochemical measurements (cyclic voltammetry (CV), linear sweep voltammetry (LSV), and ampero- 
metric measurements). The CV and LSV measurements were generally run between +0.2 and $+1 \mathrm{~V}$ vs. $\mathrm{Ag} / \mathrm{AgCl}$, with a scan rate of $10 \mathrm{mV} \cdot \mathrm{s}^{-1}$.

\subsection{Chemicals}

All chemicals, including ammonium sulfate (Reactivul Bucuresti), boric acid (SigmaAldrich, Sternheim, Germany), sodium chloride (Reactivul Bucuresti, Bucharest, Romania), potassium ferrocyanide (Sigma-Aldrich, Sternheim, Germany), potassium chloride (SigmaAldrich, Sternheim, Germany), L-tryptophan (Sigma-Aldrich, Sternheim, Germany), and dimethylformamide (DMF; JTBaker, HPLC grade, Sternheim, Germany) were used without further purification. Double-distilled water produced with Fistreem Cyclon equipment was employed to prepare all electrolyte solutions.

\subsection{Synthesis of Graphene by Electrochemical Exfoliation of Graphite Rods (EGr)}

The graphene sample was prepared by electrochemical exfoliation of graphite rods, as described in the following: two electrochemical cells filled with solutions containing $0.05 \mathrm{M}$ $\left(\mathrm{NH}_{4}\right)_{2} \mathrm{SO}_{4}+0.1 \mathrm{M} \mathrm{H}_{3} \mathrm{BO}_{3}+0.05 \mathrm{M} \mathrm{NaCl}$ were connected to the exfoliation system. The exfoliation was performed by applying a constant voltage of $12 \mathrm{~V}$ between the graphite rods (anode and cathode), while the temperature was kept constant $\left(18^{\circ} \mathrm{C}\right)$ with a temperaturecontrolled cryostat (Figure 1). In order to minimize the heat generated in the reaction cells, short pulses of current were applied for a certain period of time $(0.8 \mathrm{~s})$, followed by short pauses $(0.2 \mathrm{~s})$. After $4 \mathrm{~h}$, the material collected from the two cells was washed with distilled water $(10 \mathrm{~L}$ ) and then dispersed by ultrasound for $30 \mathrm{~min}$ in $125 \mathrm{~mL}$ water. Then, it was filtered on white-ribbon paper and dried by lyophilization. The sample was denoted as EGr.

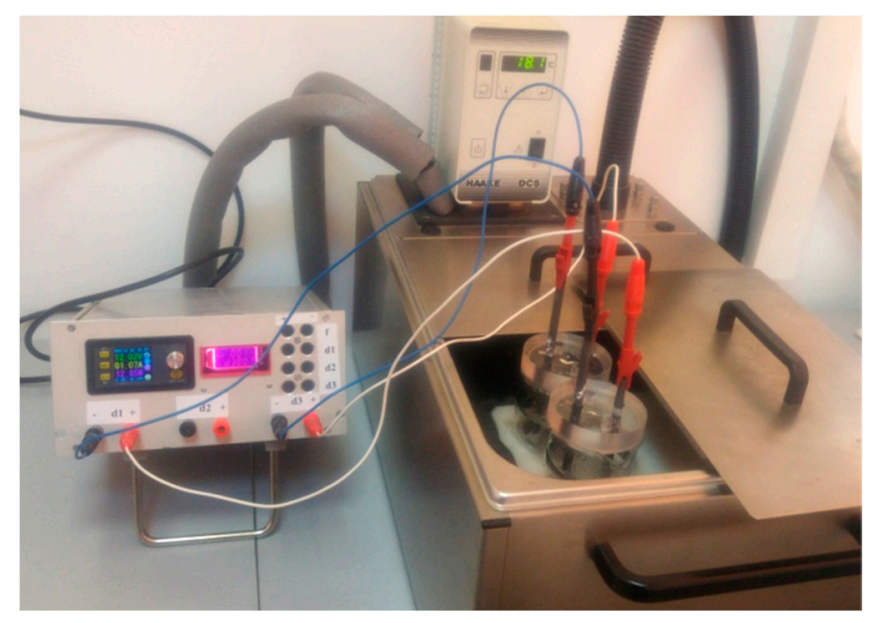

Figure 1. The experimental setup employed for the electrochemical exfoliation of graphite rods with pulses of current.

\subsection{Preparation of a Graphene-Modified Electrode (EGr/GC)}

The graphene sample previously dispersed in $N, N$-dimethylformamide $(1 \mathrm{mg} / \mathrm{mL})$ was sonicated for 3 min with a finger device (SONICS Vibra-Cell). Next, a volume of $10 \mu \mathrm{L}$ from the graphene suspension was drop-casted onto a clean GC surface and dried at room temperature for $24 \mathrm{~h}$. The schematic representation of GC modification with the EGr sample is shown in Scheme 1. 


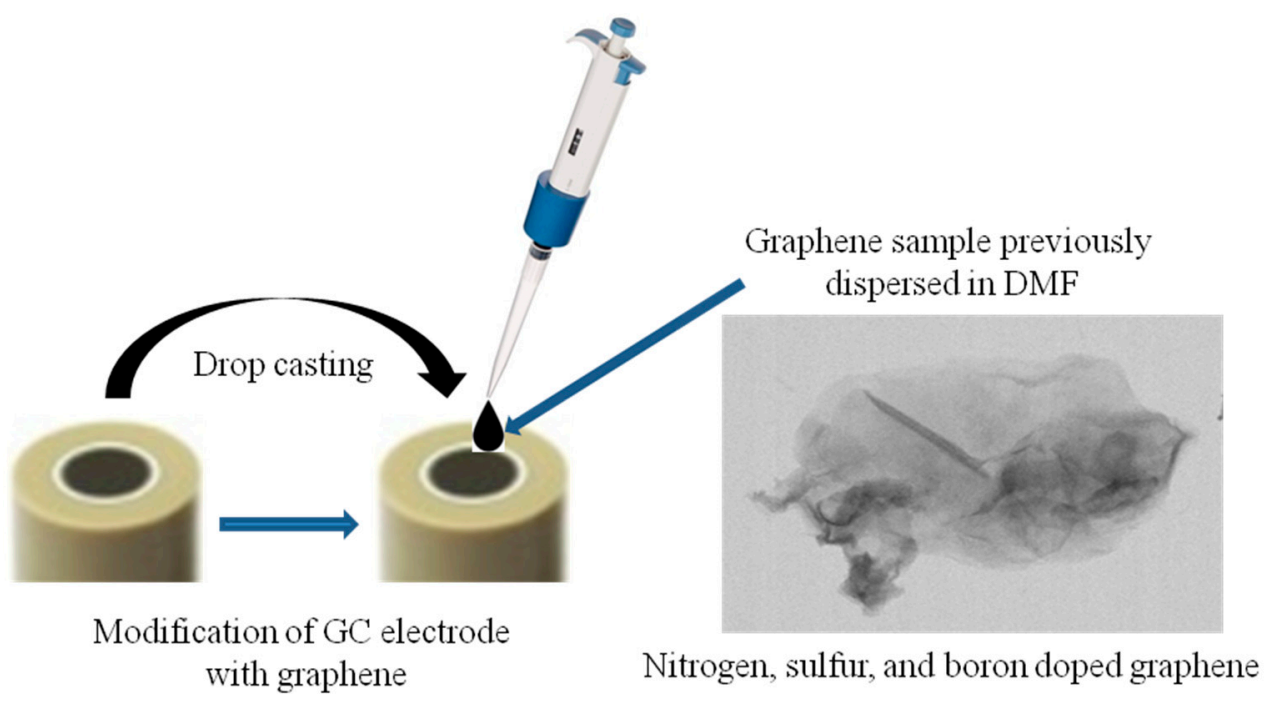

Scheme 1. Schematic representation of glassy carbon electrode (GC) modification with the graphene sample previously dispersed in dimethylformamide (DMF).

\section{Results and Discussion}

\subsection{Morphological and Structural Characterization of the EGr Sample}

Scanning and transmission electron microscopy (SEM/TEM) techniques were employed for the morphological characterization of the graphene sample. Representative images are presented in Figure 2, where one can see smooth and large areas corresponding to the basal plane of graphene, along with sharp edges where there is graphene layer roll-up. The darker regions in the TEM image represent multilayer graphene, which is formed due to the strong $\pi-\pi$ stacking interaction between single-layer graphene.
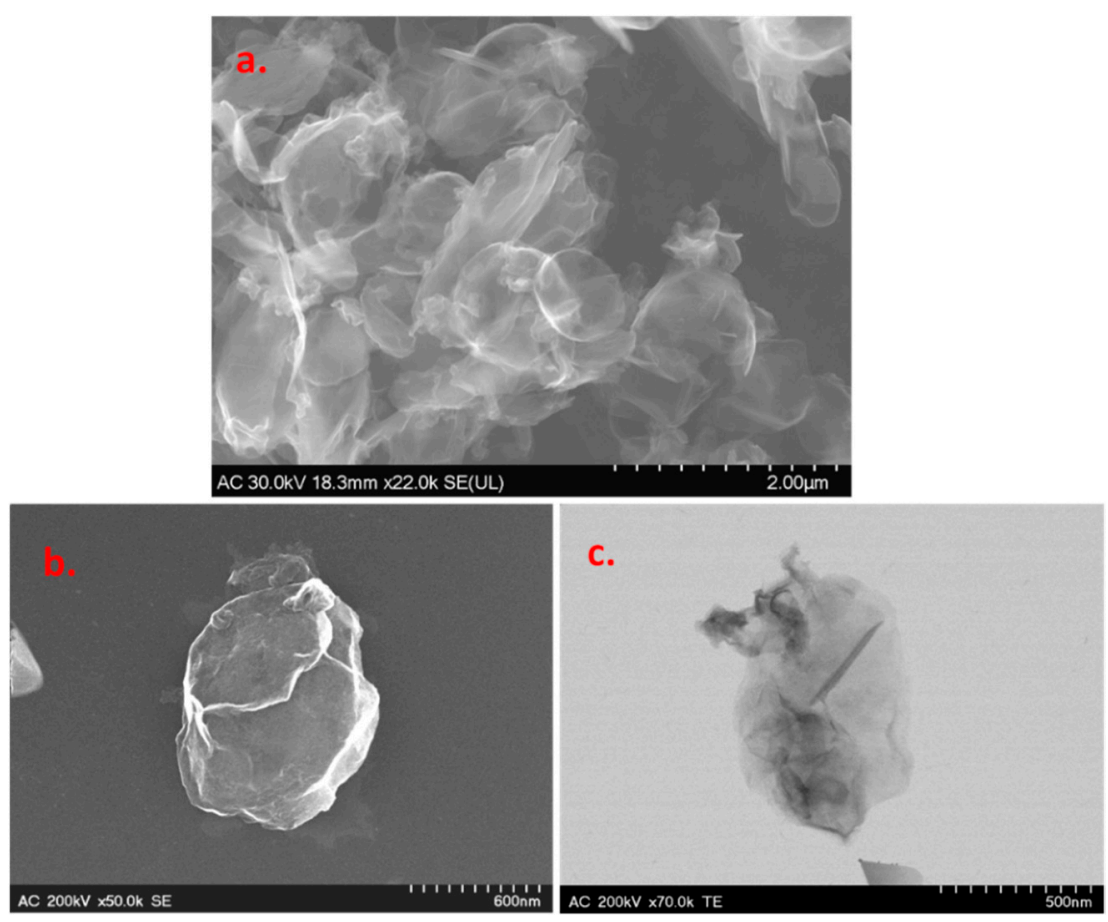

Figure 2. Representative SEM (a,b) and TEM (c) images of the graphene sample.

Structural characterization of the graphene sample was next performed by XRD, FTIR, and XPS. Figure 3 presents the XRD pattern of the sample, where three main peaks can be observed: the first one is at around $10^{\circ}$ and corresponds to the reflexions of graphene oxide 
(GO) flakes; the second and third peaks appear at around $21^{\circ}$ and $26^{\circ}$, respectively, and are due to the reflexions of few-layer (FLG) and multi-layer graphene (MLG). The XRD technique was previously used to characterize graphene-based materials and to determine the average number of graphene layers (n), the interlayer spacing $(\mathrm{d})$, the mean crystallite size (D), and the amount (\%) of GO, FLG, and MLG within the sample [27-29].

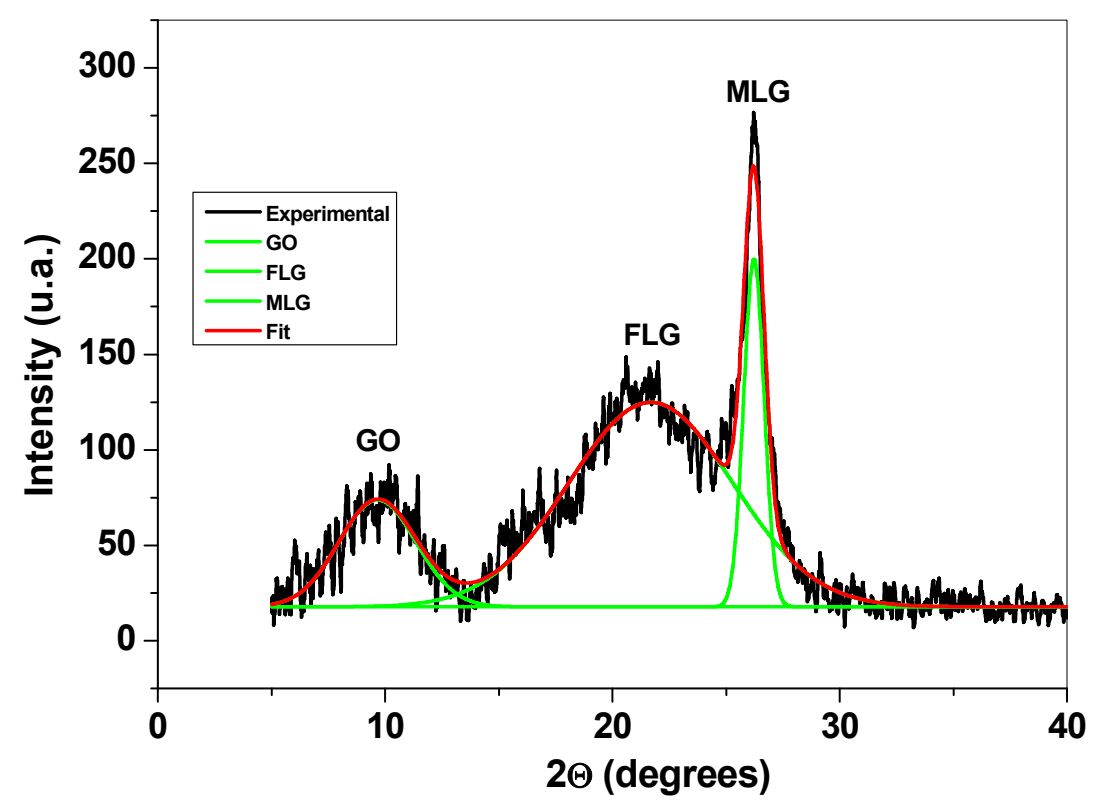

Figure 3. The XRD pattern of the graphene sample and the corresponding deconvoluted peaks.

For each peak, the $D$ value was calculated from the full width at half maximum (FWHM) using the Debye-Scherrer equation (Equation (1)):

$$
D=\frac{0.9 * \lambda}{\beta * \cos \theta}
$$

where $\lambda$ is the X-ray wavelength, $\beta$ is FWHM expressed in radians, and $\theta$ is half the diffraction angle of the peak (in degrees), corresponding to interlayer distance, $d$. The $d$ value was found with the Bragg equation $(d=\lambda / 2 \sin \theta)$, while the average number of layers, $n$, was calculated from the relation $n=D / d$ [30].

The structural parameters obtained from the diffraction pattern are presented in Table 1. From this table, one can see that the sample contains a large amount of few-layer graphene $(69 \%)$, along with smaller amounts of multi-layer graphene $(14 \%)$ and graphene oxide $(17 \%)$.

Table 1. Structural parameters obtained from the corresponding XRD pattern: graphene crystallite size $(D)$, interlayer distance $(d)$, average number of layers $(n)$, and their amount $(\%)$ within the graphene sample.

\begin{tabular}{cccccc}
\hline Sample & $\boldsymbol{2} \boldsymbol{\theta}(\mathbf{d e g})$ & $\boldsymbol{D}(\mathbf{n m})$ & $\boldsymbol{d}(\mathbf{n m})$ & $\boldsymbol{n}$ & $\begin{array}{c}\text { Amount } \\
\mathbf{( \% )}\end{array}$ \\
\hline \multirow{3}{*}{ EGr } & $9.66(\mathrm{GO})$ & 2.48 & 0.92 & $\sim 3$ & 17 \\
& $21.68(\mathrm{FLG})$ & 1.18 & 0.41 & $\sim 3$ & 69 \\
& $26.22(\mathrm{MLG})$ & 10.1 & 0.34 & $\sim 30$ & 14 \\
\hline
\end{tabular}

In order to prove the presence of heteroatoms within the graphene sample, the FTIR spectrum (Figure $4 a, b$ ) was recorded and interpreted, in good agreement with the literature data. The vibration bands identified in the FTIR spectrum of the sample can be assigned as follows: the broad band at $3430 \mathrm{~cm}^{-1}$ is due to -OH and $\mathrm{NH}_{2}$ stretching [31,32]; 2923 
and $2853 \mathrm{~cm}^{-1}$ is assigned to asymmetric and symmetric stretching of $-\mathrm{CH}_{2}$ [33]; 1744sh and $1709 \mathrm{~cm}^{-1}$ is assigned to Ar-COOH stretching and $\mathrm{C}=\mathrm{O}$ stretching $[29,34] ; 1630 \mathrm{~cm}^{-1}$ is assigned to $-\mathrm{NH}_{2}$ and aromatic $\mathrm{C}=\mathrm{C}$ stretching; $1583 \mathrm{~cm}^{-1}$ is assigned to $\mathrm{C}=\mathrm{C}$ and $\mathrm{C}=\mathrm{N}$ stretching [31]; $1546 \mathrm{sh} \mathrm{cm}^{-1}$ to $\mathrm{C}=\mathrm{C}$ stretching [34], $1400 \mathrm{~cm}^{-1}$ to $-\mathrm{COO}^{-}$stretching; $1384 \mathrm{~cm}^{-1}$ to $\mathrm{C}_{\mathrm{ar}}-\mathrm{N}$ stretching and $-\mathrm{OH}$ deformation [31].
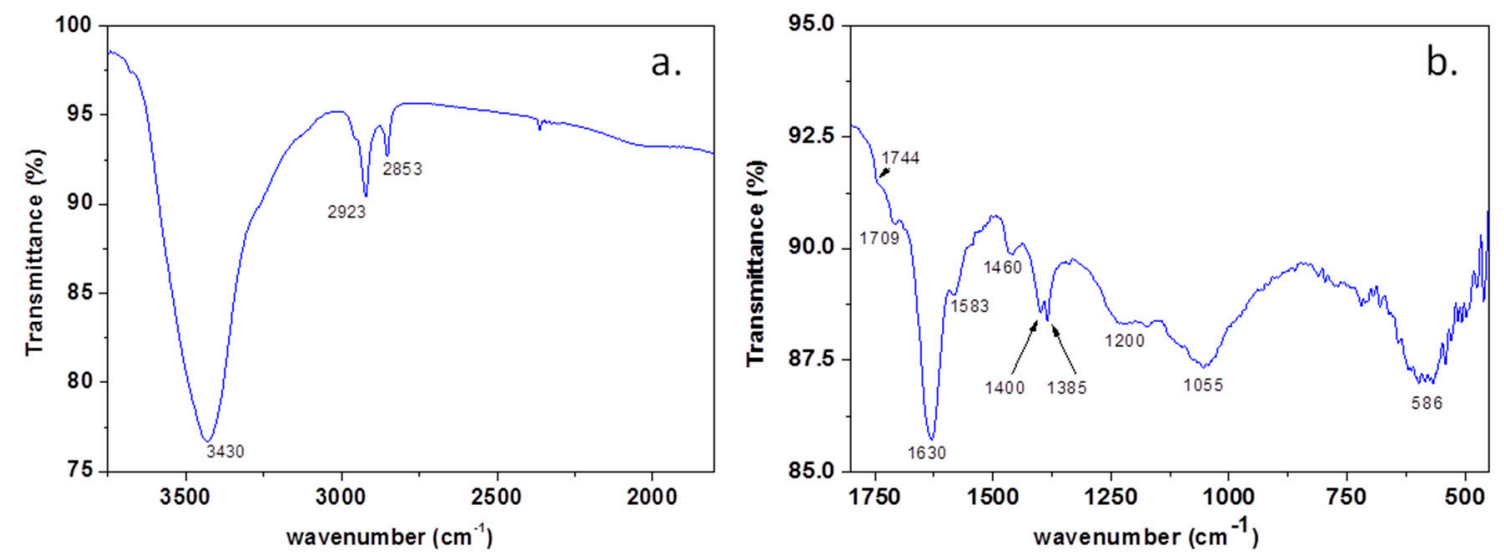

Figure 4. The FTIR spectrum of the graphene sample within $4000-2500 \mathrm{~cm}^{-1}$ (a) and $2000-450 \mathrm{~cm}^{-1}$ (b).

The broad band between $1276-1135 \mathrm{~cm}^{-1}$ is due to the overlapping of $-\mathrm{OH}$ bending and C-O-C and B-C stretching; 1100-950 $\mathrm{cm}^{-1}$, with maxima at $1055 \mathrm{~cm}^{-1}$ of $-\mathrm{C}-\mathrm{O}$ and B-O-B stretching; 670-500 $\mathrm{cm}^{-1}$, with maxima at $586 \mathrm{~cm}^{-1}$ of O-B-O stretching [31,32,34].

The XPS investigation of the graphene sample further confirms the presence of heteroatoms within the sample (N, S, B). The chemical composition of the sample was estimated from the survey spectrum (data not shown), and the elemental concentrations are shown in Table 2. Here, one can see that $S$ and B have similar concentrations (2.5 and 3 at $\%$, respectively) while $\mathrm{N}$ has a lower concentration of 1.7 at $\%$.

Table 2. Elemental concentrations of C, N, S, O, and B in the EGr sample.

\begin{tabular}{cccccc}
\hline Sample & \multicolumn{5}{c}{ Elemental Concentration } \\
\hline \multirow{2}{*}{ EGr } & $\mathrm{C}$ & $\mathrm{N}$ & $\mathrm{S}$ & $\mathrm{O}$ & $\mathrm{B}$ \\
\cline { 2 - 6 } & $70.3 \%$ & $1.7 \%$ & $2.5 \%$ & $22.4 \%$ & $3 \%$ \\
\hline
\end{tabular}

The obtained core level spectra O1s, C1s, S2p, B1s, and N1s confirmed the presence of the constituent elements in the graphene sample. The $\mathrm{C} 1 \mathrm{~s}$ high-resolution spectrum of the obtained sample (Figure 5) presents an asymmetrical, well-defined structure that can be deconvoluted into five distinct species, resulting in an FWHM average of 1.4-2 eV per peak, which, according to the literature, is within reasonable limits [35-37].

The identified components correspond to B-C bonds at $283 \mathrm{eV}, \mathrm{sp}^{2}$ graphite $284.2 \mathrm{eV}$, $\mathrm{C}-\mathrm{N}, \mathrm{C}-\mathrm{S}$, and $\mathrm{C}-\mathrm{O}$ bonds at $285 \mathrm{eV}, \mathrm{N}-\mathrm{Sp} 2-\mathrm{C}$ bonds at $286.5 \mathrm{eV}$, and $\mathrm{N}-\mathrm{C}=\mathrm{O}$ bonds at $288.4 \mathrm{eV}$ [38-41].

From the O1s deconvolution, it can be seen that three main components are present around 531.3, 532.4, and $533.2 \mathrm{eV}$ in the investigated sample, which, according to the literature, can be attributed to $\mathrm{N}-\mathrm{C}=\mathrm{O}, \mathrm{C}-\mathrm{O} / \mathrm{B}-\mathrm{O} / \mathrm{S}-\mathrm{O}$, and $\mathrm{O}=\mathrm{C}-\mathrm{O}$. A small contribution is present in the region of high values of the binding energy due to the adsorbed water molecules. 


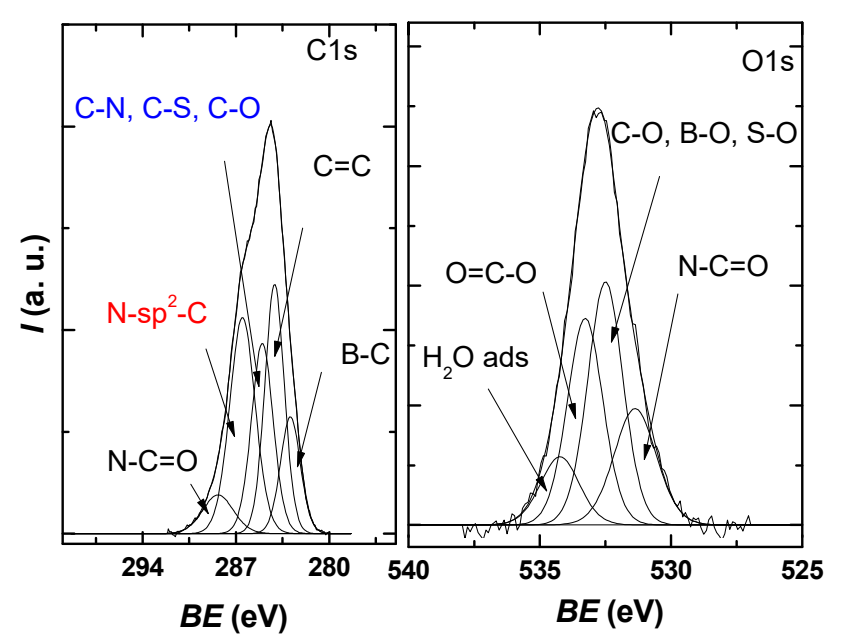

Figure 5. $\mathrm{C} 1 \mathrm{~s}$ and O1s XPS high-resolution spectra for the investigated sample, each with the deconvolution into characteristic components.

Figure 6 shows that the N1s spectra can be deconvoluted into three component peaks attributed to pyridinic-N (398.8 eV), pyrrolic-N (400.4 eV), and substitutional/graphitic-N $(401.6 \mathrm{eV})[42,43]$. Two sulfur species are observed in the S2p spectrum: the peak at $168.6 \mathrm{eV}$, which corresponds to C-S-H species, and the peak at $170.3 \mathrm{eV}$, which can be associated with $-\mathrm{C}-\mathrm{SO}_{3}-\mathrm{C}$ - sulfate groups [44].
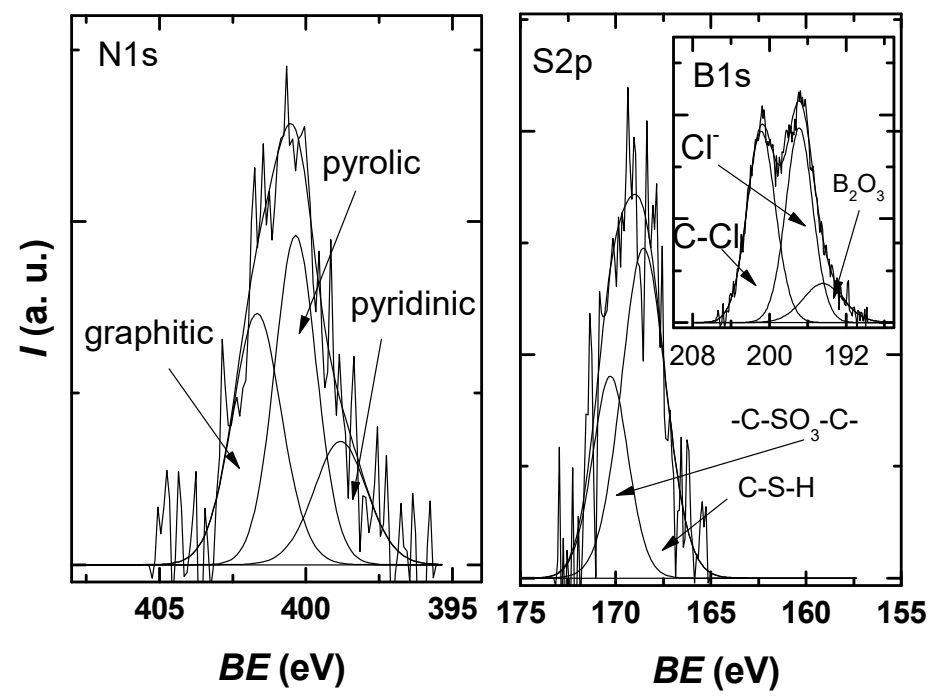

Figure 6. N1s and S2p XPS high-resolution spectra for the investigated sample, each with the deconvolution into characteristic components.

The high-resolution spectrum of B1s was deconvoluted using three components-the peak at $196.4 \mathrm{eV}$ can be attributed to $\mathrm{B}_{2} \mathrm{O}_{3}$ species; the peak at $196.9 \mathrm{eV}$ can be attributed to inorganic chlorine from a chloride salt with $\mathrm{Na}, \mathrm{K}$; the peak at $200 \mathrm{eV}$ that is indicative of chlorine atoms covalently bonded to sp2 C-as reported for organochlorine compounds or due to $\mathrm{Cl}-\mathrm{C}=\mathrm{O}$ bonds $[45,46]$.

\subsection{Electrochemical Studies}

Before testing the electrocatalytic properties of the graphene-modified electrode towards L-tryptophan oxidation, the influence of the solution $\mathrm{pH}$ was studied. Figure $7 \mathrm{a}$ shows the CV response of $10^{-4} \mathrm{M}$ L-tryptophan in PBS solutions of various $\mathrm{pH}$ (from 6 to 8), recorded with an EGr/GC electrode (scan rate: $10 \mathrm{mV} / \mathrm{s}$ ). A well-defined oxidation peak can be observed at the potential of $+0.72 \mathrm{~V}$ ( $\mathrm{pH} 6 \mathrm{PBS})$ that slightly shifts to lower 
potentials with the increase of $\mathrm{pH}$ (e.g., $+0.65 \mathrm{~V}$ in $\mathrm{pH} 8 \mathrm{PBS}$ ). A small reduction peak is present in the reverse scan, at $+0.19 \mathrm{~V}$, which can be attributed to the reduction of the oxidized intermediate of tryptophan [47]. In Figure $7 \mathrm{~b}$, one can see that the oxidation peak has similar values in slightly acidic solutions $\left(2.9 \times 10^{-6} \mathrm{~A}\right)$ but it strongly decreased at higher $\mathrm{pH}$ values. Based on the above results, the next experiments were recorded in pH 6 PBS solutions. Considering the results from the present study and the previous literature data [20,48], the possible electrochemical oxidation mechanism for L-tryptophan is as follows (see Scheme 2):
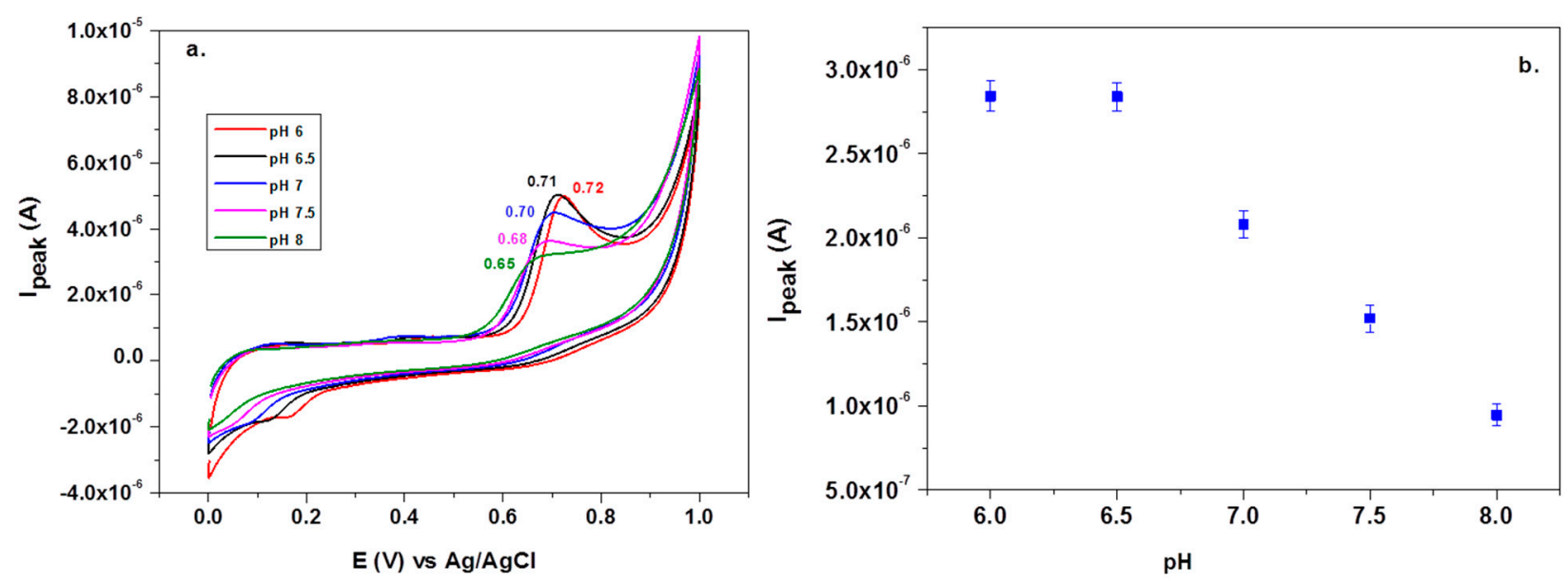

Figure 7. Cyclic voltammetry $(\mathrm{CV})$ recorded with graphene-modified electrodes in solutions containing $10^{-4} \mathrm{M}$ L-tryptophan in PBS solutions of various $\mathrm{pH}: 6,6.5,7,7.5$, and 8 (a). Variations of the peak current $\left(\mathrm{I}_{\text {peak }}\right)$ with the solution $\mathrm{pH}(\mathbf{b})$.<smiles>NC(Cc1c[nH]c2ccccc12)C(=O)O</smiles>

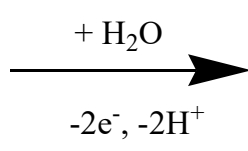<smiles>NC(CC1C=NC2=CC(=O)C=CC21)C(=O)O</smiles>

Scheme 2. The suggested mechanism for electrochemical oxidation of L-tryptophan.

Under the optimized conditions, L-tryptophan was quantitatively analyzed by linear sweep voltammetry; the corresponding recordings at various concentrations $\left(1 \times 10^{-7}-1 \times 10^{-4} \mathrm{M}\right)$ can be seen in Figure $8 \mathrm{a}, \mathrm{b}$. Significant differences are noticed between the bare and graphene-modified electrodes. In the first place, the peak potential is very high for the bare GC electrode $(+0.91 \mathrm{~V})$ compared with that of the graphenemodified electrode $(+0.72 \mathrm{~V})$. In addition, the peak intensity is three times larger for the EGr/GC electrode, confirming that the graphene layers considerably increase the transfer of electrons across the electrode/solution interface.

The corresponding calibration curves obtained by plotting $\mathrm{I}_{\text {peak }}$ versus L-tryptophan concentrations are represented in Figure 8c. The oxidation peak current linearly increased with the concentration, and the corresponding regression equation was $\mathrm{I}_{\text {peak }}=1.33 \times 10^{-8}$ $+0.0078 \times C, R^{2}=0.9781$ (for the bare GC electrode) and $I_{\text {peak }}=-2.58 \times 10^{-8}+0.028 \times C$, $\mathrm{R}^{2}=0.9978$ (for the EGr/GC electrode). As expected, the EGr/GC electrode had high sensitivity $(0.028 \mathrm{~A} / \mathrm{M})$ and a low limit of detection $\left(3.03 \times 10^{-7} \mathrm{M}\right)$. The detection limit was calculated from the limit of determination (LOD) divided by 3.3. LOD is the lowest concentration of L-tryptophan for the electrode to give an oxidation signal. 

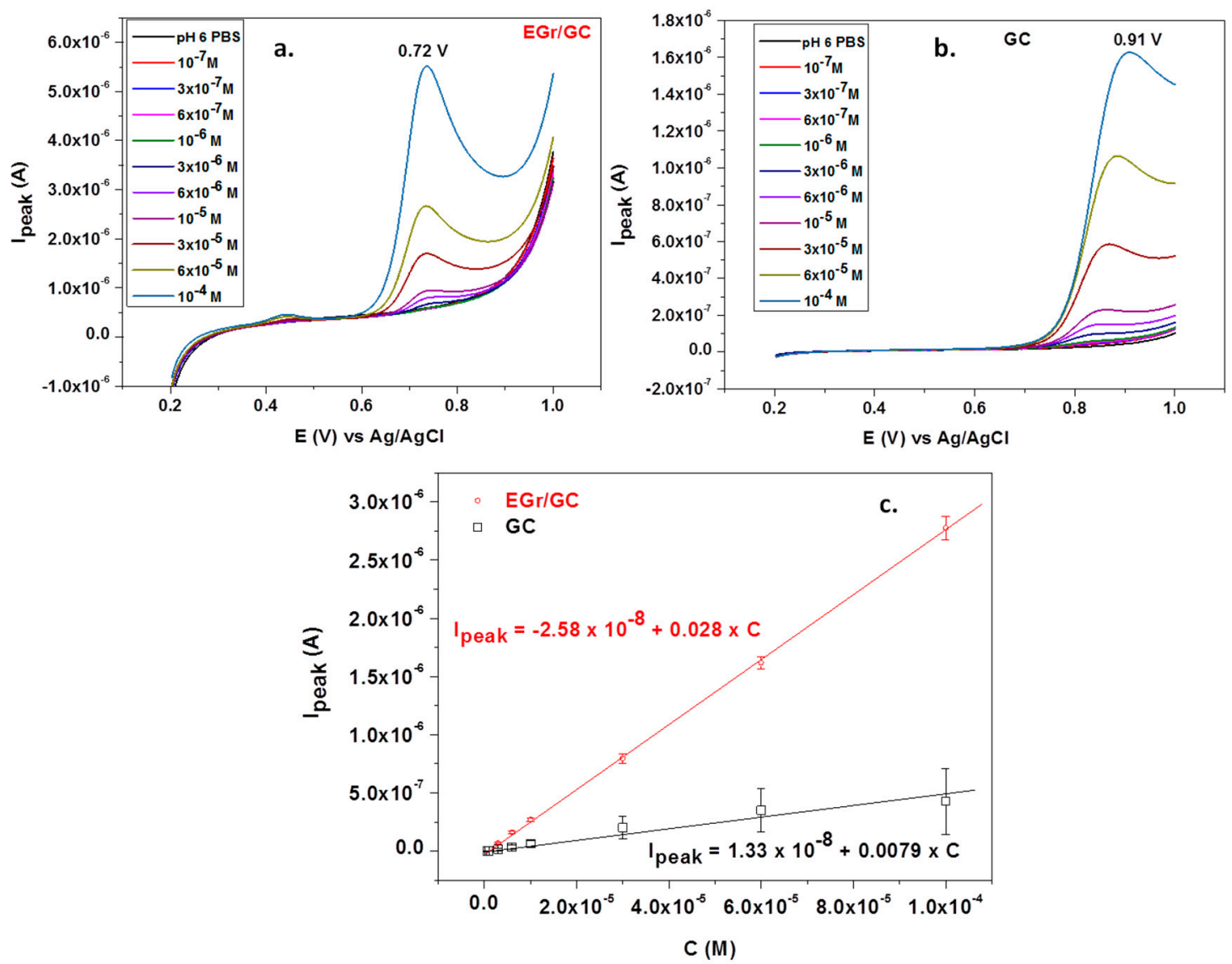

Figure 8. Linear sweep voltammograms recorded with a graphene-modified electrode (a) and a bare GC electrode (b) in the presence of different concentrations of L-tryptophan (supporting electrolyte: $\mathrm{pH} 6 \mathrm{PBS}$; scan rate: $10 \mathrm{mV} / \mathrm{s}$ ); the corresponding calibration plots for bare GC and EGr/GC electrodes (c).

According to several studies, the oxidation products of L-tryptophan can be easily adsorbed onto the electrode's surface, fouling the electrical signal. Therefore, we tested the reproducibility of the signals given by the bare GC and EGr/GC electrodes in three successive measurements. After each measurement, the electrode was immersed in distilled water for $10 \mathrm{~min}$, and then 10 voltammetric scans were recorded between the $+0.2 \ldots+1 \mathrm{~V}$ potential range $(10 \mathrm{mV} / \mathrm{s} ; \mathrm{pH} 6 \mathrm{PBS})$. The results can be seen in Supporting Information Material (Figure S1a,b) indicating very weak adsorption of the oxidation products on the EGr/GC electrode in comparison with the bare GC electrode. The relative standard deviation (RSD \%) in a $10^{-4}$ M L-tryptophan solution was 3.72\% for EGr/GC and $65.9 \%$ for GC. The results further confirmed the advantages of using the EGr material for electrode modification.

Excellent signals were also obtained when the EGr/GC electrode was polarized at a potential of $+0.72 \mathrm{~V}$ and various concentrations of L-tryptophan were added to the supporting electrolyte, pH 6 PBS (Figure 9a-amperometric measurement). The corresponding calibration curve obtained after subtracting the background current is represented in Figure $9 \mathrm{~b}$. In this case, the calibration plot has two linear ranges: the first one from $1 \times 10^{-7}$ to $2 \times 10^{-5} \mathrm{M}$ and the second one from $2 \times 10^{-5}$ to $10^{-4} \mathrm{M}$. Above $10^{-4} \mathrm{M}$, a saturation effect occurs and the curve deviates from linearity. Most important, in the low concentration range $\left(1 \times 10^{-7}\right.$ to $\left.2 \times 10^{-5} \mathrm{M}\right)$, electrode sensitivity is very high $(0.044 \mathrm{~A} / \mathrm{M})$ and the limit of detection is even lower $\left(3.03 \times 10^{-8} \mathrm{M}\right)$. 

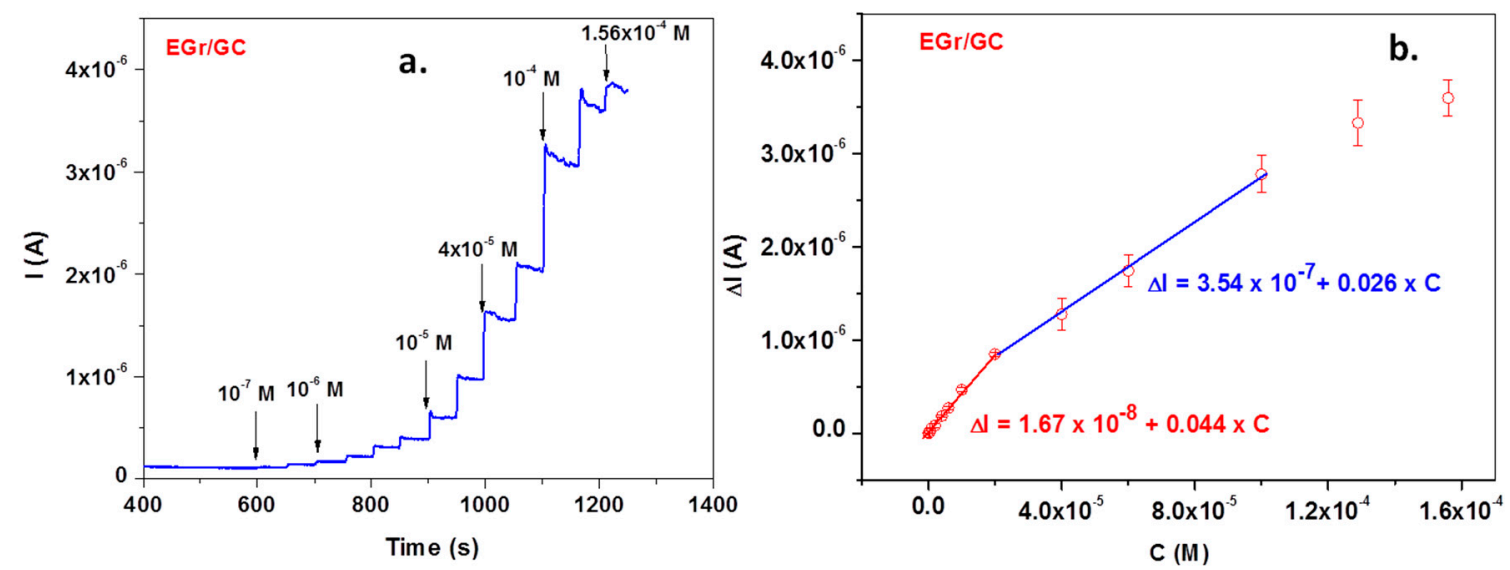

Figure 9. Amperometric curve recorded with the EGr/GC electrode in $\mathrm{pH} 6$ PBS-supporting electrolyte (at $+0.72 \mathrm{~V})$ after adding various concentrations of L-tryptophan (TRP) (a). The corresponding calibration plot, showing $\mathrm{t}$ wo linear ranges (b).

The influence of some interfering species, such as dopamine (DA), uric acid (UA), ascorbic acid (AA) and melatonin (MEL), was next studied. DA and UA generally coexist with L-tryptophan in biological fluids; therefore, the study of their influence on TRP oxidation is highly important. Dopamine and uric acid can be electrochemically oxidized, and the corresponding peaks appear at potentials lower than that of L-tryptophan (Figure 10). Hence, dopamine gives a signal at $+0.25 \mathrm{~V}$, while uric acid oxidation takes place at $+0.39 \mathrm{~V}$. As expected, their influence on the L-tryptophan oxidation peak is closely related to their concentrations. This can be clearly seen in the LSVs recorded with the EGr/GC electrode in the presence and absence of interfering species. At low concentrations of interfering species $\left(10^{-6}\right.$ and $\left.10^{-5} \mathrm{M}\right)$, the peak value of TRP is slightly affected. At higher concentrations $\left(10^{-4} \mathrm{M}\right)$, a shift in the background current can be observed, accompanied by an increase of the TRP oxidation peak. In contrast, the peak potential of TRP $(+0.72 \mathrm{~V})$ did not change, regardless of DA and UA concentrations.

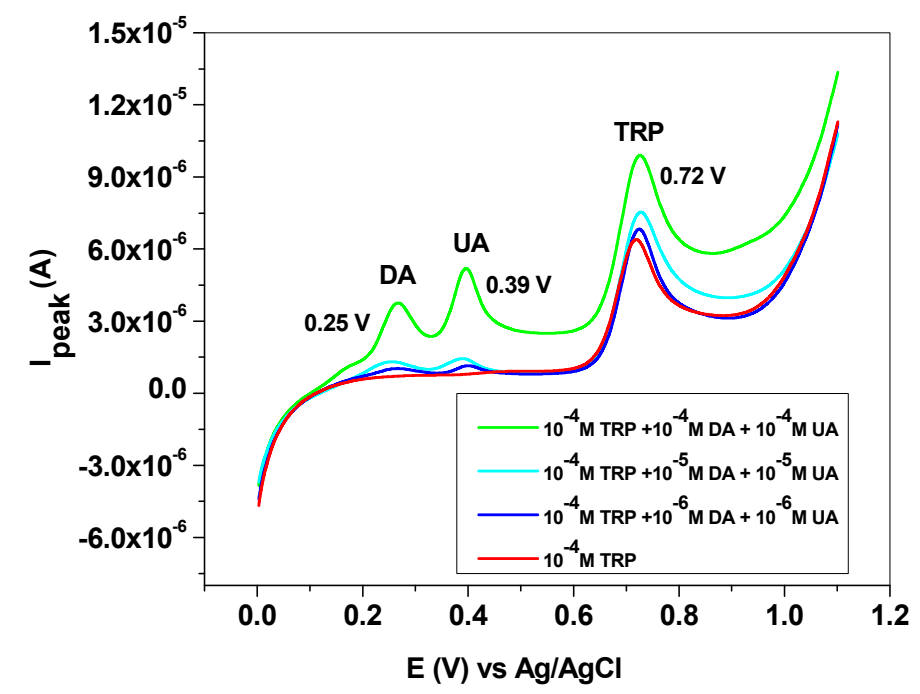

Figure 10. Linear sweep voltammetry (LSV) recorded with the EGr/GC electrode in the absence and presence of interfering species, dopamine, and uric acid. Scan rate: $10 \mathrm{mV} / \mathrm{s}$; supporting electrolyte: pH 6 PBS.

Melatonin is a hormone produced in the tryptophan/serotonin pathway and has a great influence on the diurnal rhythm. It also influences the reproductive and immune systems and gastrointestinal motility. Its synthesis within the body is regulated by the blue light spectrum (e.g., 446 to $477 \mathrm{~nm}$ ), and, during the night, it is secreted by the pineal gland, inducing neural and endocrine effects [14]. The electrochemical oxidation of melatonin 
takes place in two steps, giving rise to two broad peaks at +0.44 and $+0.73 \mathrm{~V}$ (blue line, Figure 11). The second peak is very close to that corresponding to L-tryptophan (+0.72 V); therefore, it may significantly influence TRP oxidation.

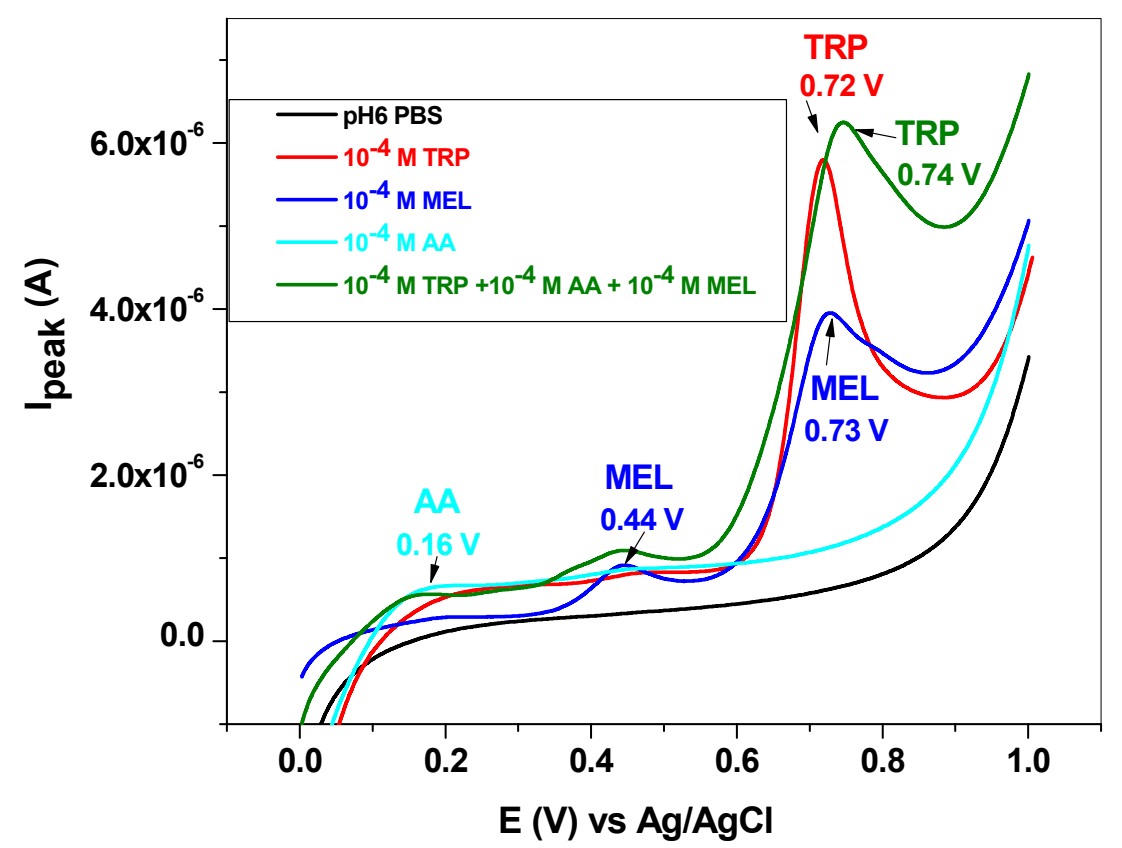

Figure 11. LSV recorded with the EGr/GC electrode in the absence and presence of interfering species, melatonin, and ascorbic acid. Scan rate: $10 \mathrm{mV} / \mathrm{s}$; supporting electrolyte: $\mathrm{pH} 6$ PBS.

Ascorbic acid or vitamin $\mathrm{C}$ has the role of cofactor in many enzymatic reactions that mediate several biological functions in the human body. It also acts as a reducing agent (antioxidant), and its deficiency in the body leads to impaired collagen synthesis. The oxidation of ascorbic acid takes place at low potential $(+0.16 \mathrm{~V})$, and the peak is weak and very broad (cyan line, Figure 11).

When mixed with L-tryptophan, the two interfering species $\left(10^{-4} \mathrm{M}\right.$ for each of them) induced the increase of the capacitive current and also shifted the TRP peak potential from 0.72 to $0.74 \mathrm{~V}$ (see the olive curve in comparison with the red curve). Concerning the peak current of L-tryptophan, its value is lower in the presence of interfering species $\left(2.7 \times 10^{-6}\right.$ versus $\left.3.02 \times 10^{-6} \mathrm{~A}\right)$, indicating that the antioxidant properties of ascorbic acid may prevent TRP oxidation.

In order to test the practical applicability of the EGr/GC-modified electrode, it was used to detect the L-tryptophan concentration in milk that was bought from the local supermarket ( $4 \%$ fat). Before measurements, $1 \mathrm{~mL}$ of milk was diluted 10-times with $\mathrm{pH}$ 6 PBS; then, increasing concentrations of TRP (also dissolved in pH 6 PBS) were added (see Figure 12). In the inset are presented the LSV curves recorded in the milk sample containing increasing concentrations of TRP (from $5 \times 10^{-5}$ to $2.5 \times 10^{-4} \mathrm{M}$ ). The final concentration of L-tryptophan in milk was determined by standard addition, and the value was found to be $90.1 \mathrm{mg} / \mathrm{L}$. The results prove that the EGr/GC-modified electrode is sensitive for L-tryptophan determination in real samples.

The performances of the EGr/GC electrode were compared with those of other modified electrodes reported in the literature (see Table 3). Here, one can see that the electrode has an excellent performance in terms of both linear range and limit of detection. 


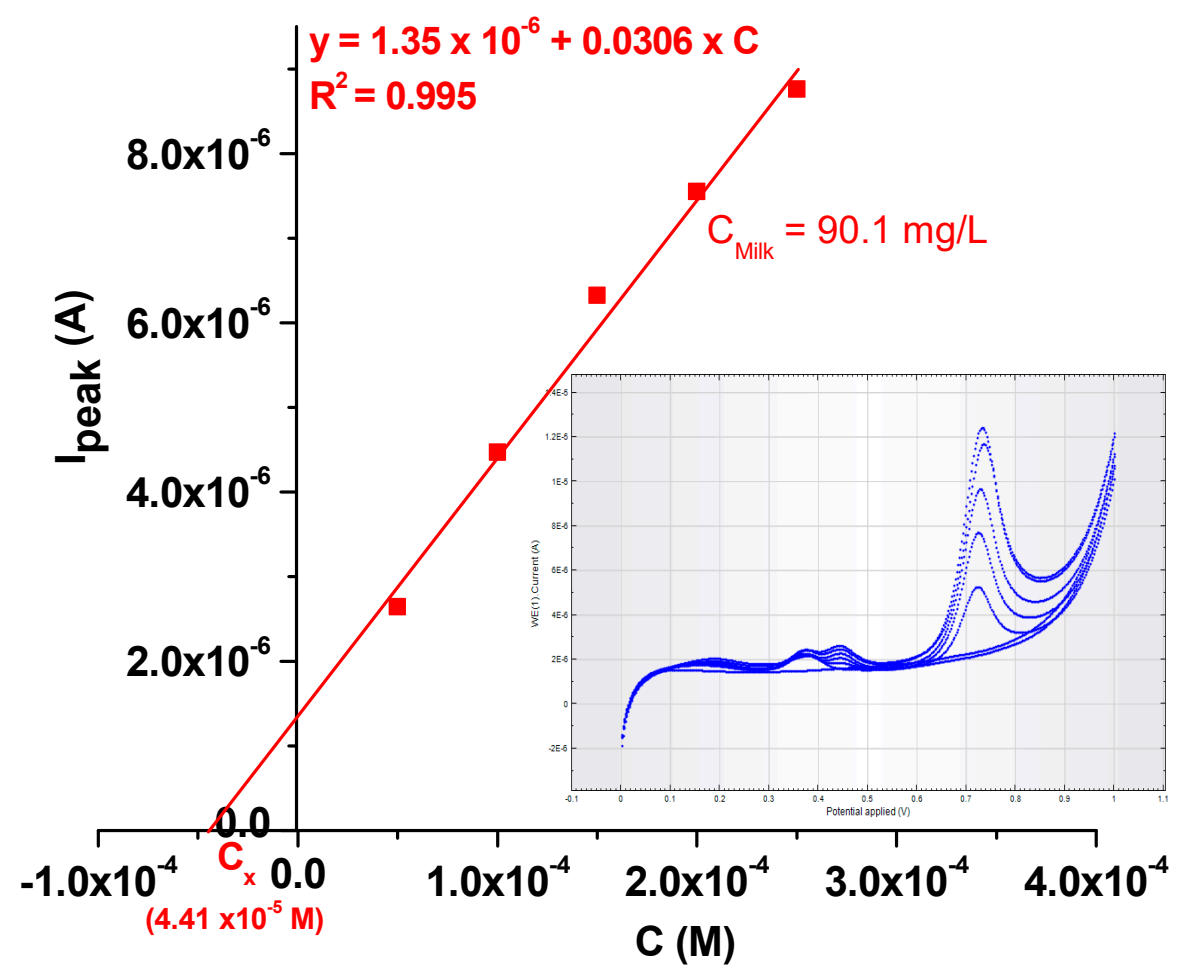

Figure 12. Calibration plot obtained with the EGr/GC electrode after standard addition of TRP in a milk sample. Inset: the LSVs recorded at various L-tryptophan concentrations (from $5 \times 10^{-5}$ to $\left.2.5 \times 10^{-4} \mathrm{M}\right)$ in milk.

Table 3. Comparison of the analytical performance of various electrodes modified with graphene-based materials.

\begin{tabular}{|c|c|c|c|}
\hline Electrode/Sensing Material & Linear Range (M) & DL (M) & Ref. \\
\hline $\begin{array}{l}\text { carbon paste electrode } / \text { nitrogen-doped graphene } \\
\text { nanosheets } / \mathrm{CuCo}_{2} \mathrm{O}_{4} \text { nanoparticles }\end{array}$ & $0.010-3.0 \times 10^{-6}$ & $0.0041 \times 10^{-6}$ & [21] \\
\hline GC/poly(L-methionine) and graphene composite film & $0.2-150 \times 10^{-6}$ & $0.017 \times 10^{-6}$ & [22] \\
\hline $\mathrm{GC} /$ reduced graphene oxide and $\mathrm{SnO}_{2}$ & $1-100 \times 10^{-6}$ & $0.04 \times 10^{-6}$ & [23] \\
\hline GC/ $\mathrm{Cu}_{2} \mathrm{O}$-nanoparticle-coated reduced graphene oxide & $0.02-20 \times 10^{-6}$ & $0.01 \times 10^{-6}$ & {$[24]$} \\
\hline GC/nitrogen-doped ordered mesoporous carbon & $\begin{array}{c}0.5-70.0 \times 10^{-6} \\
70.0-200.0 \times 10^{-6}\end{array}$ & $3.5 \times 10^{-8}$ & [49] \\
\hline $\mathrm{GC} / \mathrm{Co}_{3} \mathrm{O}_{4}$ nanoparticles-decorated graphene & $0.05-10 \times 10^{-6}$ & $0.01 \times 10^{-6}$ & {$[50]$} \\
\hline GC/nitrogen-, sulfur-, and boron-doped graphene & $1 \times 10^{-7}-2 \times 10^{-5}$ & $3.03 \times 10^{-8}$ & This work \\
\hline
\end{tabular}

\section{Conclusions}

A triple-doped (N, S, B) graphene sample was prepared by electrochemical exfoliation of graphite rods in a solution containing $0.05 \mathrm{M}\left(\mathrm{NH}_{4}\right)_{2} \mathrm{SO}_{4}+0.1 \mathrm{M} \mathrm{H}_{3} \mathrm{BO}_{3}+0.05 \mathrm{M} \mathrm{NaCl}$. After morphological and structural characterization of the graphene sample, its electrocatalytic properties towards L-tryptophan oxidation were studied. Significant differences were noticed between the bare GC and graphene-modified electrodes. In the first place, the TRP peak potential was very high for the bare electrode $(+0.91 \mathrm{~V})$ in comparison with that of the EGr/GC electrode $(+0.72 \mathrm{~V})$. Second, the peak intensity was three times larger for the EGr/GC electrode, confirming that the graphene layers considerably increased the transfer of electrons across the electrode/solution interface. In order to test the practical applicability of the EGr/GC-modified electrode, this was used to detect the L-tryptophan concentration in milk ( $4 \%$ fat). Its concentration was determined by standard addition, and 
the value was found to be $90.1 \mathrm{mg} / \mathrm{L}$, proving that the electrode was sensitive enough for real sample analysis.

Supplementary Materials: The following are available online at https:/ /www.mdpi.com/2079-637 4/11/2/36/s1, Figure S1: Calibration plots obtained from 3 successive measurements recorded with EGr/GC (a) and GC (b) electrodes.

Author Contributions: F.P. and C.V. recorded and interpreted the electrochemical measurements; M.C. edited the manuscript; I.K. recorded and interpreted the FTIR spectrum; T.R. interpreted the XPS analysis; B.I.C. handled the software; V.M. built-up the experimental setup; S.P. wrote the final manuscript. All authors have read and agreed to the published version of the manuscript.

Funding: This work was supported by a grant from the Romanian Ministry of Research and Innovation (CNCS-UEFISCDI, project number PN-III-P4-ID-PCCF-2016-0006) within PNCDI III.

Institutional Review Board Statement: Not applicable.

Informed Consent Statement: Not applicable.

Data Availability Statement: Data will be provided upon reasonable request to the corresponding author.

Acknowledgments: The authors are grateful to Alexandra Ciorita for SEM/TEM recordings of the graphene sample, Alexandru Turza for recording the XRD spectrum, and Cristian Leostean for recording the XPS spectrum.

Conflicts of Interest: The authors declare no conflict of interest.

\section{References}

1. Cho, I.H.; Kim, D.H.; Park, S. Electrochemical biosensors: Perspective on functional nanomaterials for on-site analysis. Biomater. Res. 2020, 24, 1-12.

2. Lemine, A.S.; Zagho, M.M.; Altahtamouni, T.M.; Bensalah, N. Graphene a promising electrode material for supercapacitors-A review. Int. J. Energy Res. 2018, 42, 4284-4300. [CrossRef]

3. Kaushal, S.; Kaur, M.; Kaur, N.; Kumari, V.; Singh, P.P. Heteroatom-doped graphene as sensing materials: A mini review. RSC Adv. 2020, 10, 28608-28629.

4. Poh, H.L.; Pumera, M. p-Element-Doped Graphene: Heteroatoms for Electrochemical Enhancement. ChemElectroChem 2015, 2, 190-199. [CrossRef]

5. Deng, H.; Zhu, M.; Jin, T.; Cheng, C.; Zheng, J.; Qian, Y. One-step synthesis of nitrogen, sulphur-codoped graphene as electrode material for supercapacitor with excellent cycling stability. Int. J. Electrochem. Sci. 2020, 15, 16-25. [CrossRef]

6. Liu, H.; Liu, Y. Controlled Chemical Synthesis in CVD Graphene. Phys. Sci. Rev. 2019, 2, 1-28.

7. Sheng, Z.H.; Shao, L.; Chen, J.J.; Bao, W.J.; Wang, F.B.; Xia, X.H. Catalyst-free synthesis of nitrogen-doped graphene via thermal annealing graphite oxide with melamine and its excellent electrocatalysis. ACS Nano 2011, 5, 4350-4358.

8. Bundaleska, N.; Henriques, J.; Abrashev, M.; Botelho do Rego, A.M.; Ferraria, A.M.; Almeida, A.; Dias, F.M.; Valcheva, E.; Arnaudov, B.; Upadhyay, K.K.; et al. Large-scale synthesis of free-standing N-doped graphene using microwave plasma. Sci. Rep. 2018, 8, 1-11. [CrossRef]

9. Subrahmanyam, K.S.; Panchakarla, L.S.; Govindaraj, A.; Rao, C.N.R. Simple method of preparing graphene flakes by an arc-discharge method. J. Phys. Chem. C 2009, 113, 4257-4259.

10. Bhushan, R.; Kumar, P.; Thakur, A.K. Catalyst-free solvothermal synthesis of ultrapure elemental N-and B-doped graphene for energy storage application. Solid State Ionics 2020, 353, 115371. [CrossRef]

11. Liu, F.; Wang, C.; Sui, X.; Riaz, M.A.; Xu, M.; Wei, L.; Chen, Y. Synthesis of graphene materials by electrochemical exfoliation: Recent progress and future potential. Carbon Energy 2019, 1, 173-199. [CrossRef]

12. Ullah, S.; Denis, P.A.; Sato, F. Triple-Doped Monolayer Graphene with Boron, Nitrogen, Aluminum, Silicon, Phosphorus, and Sulfur. ChemPhysChem 2017, 18, 1864-1873. [CrossRef] [PubMed]

13. Palego, L.; Betti, L.; Rossi, A.; Giannaccini, G. Tryptophan biochemistry: Structural, nutritional, metabolic, and medical aspects in humans. J. Amino Acids 2016, 2016. [CrossRef]

14. Richard, D.M.; Dawes, M.A.; Mathias, C.W.; Acheson, A.; Hill-Kapturczak, N.; Dougherty, D.M. L-tryptophan: Basic metabolic functions, behavioral research and therapeutic indications. Int. J. Tryptophan Res. 2009, 2, 45-60. [CrossRef]

15. Blume, C.; Garbazza, C.; Spitschan, M. Effects of light on human circadian rhythms, sleep and mood. Somnologie 2019, 23, 147-156. [CrossRef] [PubMed]

16. Van Lee, L.; Cai, S.; Loy, S.L.; Tham, E.K.H.; Yap, F.K.P.; Godfrey, K.M.; Gluckman, P.D.; Shek, L.P.C.; Teoh, O.H.; Goh, D.Y.T.; et al. Relation of plasma tryptophan concentrations during pregnancy to maternal sleep and mental well-being: The GUSTO cohort. J. Affect. Disord. 2018, 225, 523-529. [CrossRef] 
17. Çevikkalp, S.A.; Löker, G.B.; Yaman, M.; Amoutzopoulos, B. A simplified HPLC method for determination of tryptophan in some cereals and legumes. Food Chem. 2016, 193, 26-29. [PubMed]

18. Li, S.; Xing, M.; Wang, H.; Zhang, L.; Zhong, Y.; Chen, L. Determination of tryptophan and tyrosine by chemiluminescence based on a luminol-N-bromosuccinimide-ZnS quantum dots system. RSC Adv. 2015, 5, 59286-59291. [CrossRef]

19. Takagai, Y.; Igarashi, S. Determination of ppb levels of tryptophan derivatives by capillary electrophoresis with homogeneous liquid-liquid extraction and sweeping method. Chem. Pharm. Bull. 2003, 51, 373-377. [CrossRef]

20. Zhu, S.; Zhang, J.; Zhao, X.E.; Wang, H.; Xu, G.; You, J. Electrochemical behavior and voltammetric determination of L-tryptophan and L-tyrosine using a glassy carbon electrode modified with single-walled carbon nanohorns. Microchim. Acta 2014, 181, 445-451. [CrossRef]

21. Tadayon, F.; Sepehri, Z. A new electrochemical sensor based on a nitrogen-doped graphene $/ \mathrm{CuCo}_{2} \mathrm{O}_{4}$ nanocomposite for simultaneous determination of dopamine, melatonin and tryptophan. RSC Adv. 2015, 5, 65560-65568. [CrossRef]

22. Wang, Y.; Ouyang, X.; Ding, Y.; Liu, B.; Xu, D.; Liao, L. An electrochemical sensor for determination of tryptophan in the presence of DA based on poly(l-methionine)/graphene modified electrode. RSC Adv. 2016, 6, 10662-10669. [CrossRef]

23. Haldorai, Y.; Yeon, S.H.; Huh, Y.S.; Han, Y.K. Electrochemical determination of tryptophan using a glassy carbon electrode modified with flower-like structured nanocomposite consisting of reduced graphene oxide and $\mathrm{SnO}_{2}$. Sens. Actuators $B$ Chem. 2017, 239, 1221-1230. [CrossRef]

24. He, Q.; Tian, Y.; Wu, Y.; Liu, J.; Li, G.; Deng, P.; Chen, D. Electrochemical sensor for rapid and sensitive detection of tryptophan by $\mathrm{a} \mathrm{Cu}_{2} \mathrm{O}$ nanoparticles- coated reduced graphene oxide nanocomposite. Biomolecules 2019, 9, 176. [CrossRef] [PubMed]

25. He, Q.; Liu, J.; Feng, J.; Wu, Y.; Tian, Y.; Li, G.; Chen, D. Sensitive voltammetric sensor for tryptophan detection by using polyvinylpyrrolidone functionalized graphene/GCE. Nanomaterials 2020, 10, 125. [CrossRef] [PubMed]

26. Yang, X.; Niu, X.; Mo, Z.; Wang, J.; Shuai, C.; Pan, Z.; Liu, Z.; Liu, N.; Guo, R. 3D Nitrogen and Sulfur Co-Doped Graphene/Integrated Polysaccharides for Electrochemical Recognition Tryptophan Enantiomers. J. Electrochem. Soc. 2019, 166, B1053-B1062. [CrossRef]

27. Razeghi, M.; Pircheraghi, G. TPU/graphene nanocomposites: Effect of graphene functionality on the morphology of separated hard domains in thermoplastic polyurethane. Polymer 2018, 148, 169-180. [CrossRef]

28. Udayabhaskar, R.; Mangalaraja, R.V.; Pandiyarajan, T.; Karthikeyan, B.; Mansilla, H.D.; Contreras, D. Spectroscopic investigation on graphene-copper nanocomposites with strong UV emission and high catalytic activity. Carbon 2017, 124, $256-262$.

29. Coroş, M.; Pogăcean, F.; Roşu, M.-C.; Socaci, C.; Borodi, G.; Mageruşan, L.; Biriş, A.R.; Pruneanu, S. Simple and cost-effective synthesis of graphene by electrochemical exfoliation of graphite rods. RSC Adv. 2016, 6, 2651-2661. [CrossRef]

30. Balzar, D. X-ray diffraction line broadening: Modeling and applications to high-Tc superconductors. J. Res. Natl. Inst. Stand. Technol. 1993, 98, 321. [CrossRef]

31. Xu, X.; Yuan, T.; Zhou, Y.; Li, Y.; Lu, J.; Tian, X.; Wang, D.; Wang, J. Facile synthesis of boron and nitrogen-doped graphene as efficient electrocatalyst for the oxygen reduction reaction in alkaline media. Int. J. Hydrog. Energy 2014, 39, 16043-16052. [CrossRef]

32. Junaid, M.; Khir, M.H.M.; Witjaksono, G.; Tansu, N.; Saheed, M.S.M.; Kumar, P.; Ullah, Z.; Yar, A.; Usman, F. Boron-Doped Reduced Graphene Oxide with Tunable Bandgap and Enhanced Surface Plasmon Resonance. Molecules 2020, 25, 3646. [CrossRef] [PubMed]

33. Coates, J. Interpretation of Infrared Spectra, A Practical Approach. Encycl. Anal. Chem. 2006, 1-23. [CrossRef]

34. Mannan, A.; Hirano, Y.; Quitain, A.T.; Koinuma, M.; Kida, T. Graphene Oxide to B, N Co-doped Graphene through Trisdimethylaminoborane Complex by Hydrothermal Implantation. Am. J. Mater. Sci. 2019, 9, 22-28.

35. Ganguly, A.; Sharma, S.; Papakonstantinou, P.; Hamilton, J. Probing the thermal deoxygenation of graphene oxide using high-resolution in situ X-ray-based spectroscopies. J. Phys. Chem. C 2011, 115, 17009-17019. [CrossRef]

36. Kundu, S.; Wang, Y.; Xia, W.; Muhler, M. Thermal stability and reducibility of oxygen-containing functional groups on multiwalled carbon nanotube surfaces: A quantitative high-resolution XPS and TPD/TPR study. J. Phys. Chem. C 2008, 112, 16869-16878. [CrossRef]

37. Moraitis, G.; Špitalský, Z.; Ravani, F.; Siokou, A.; Galiotis, C. Electrochemical oxidation of multi-wall carbon nanotubes. Carbon 2011, 49, 2702-2708. [CrossRef]

38. Stankovich, S.; Dikin, D.A.; Piner, R.D.; Kohlhaas, K.A.; Kleinhammes, A.; Jia, Y.; Wu, Y.; Nguyen, S.B.T.; Ruoff, R.S. Synthesis of graphene-based nanosheets via chemical reduction of exfoliated graphite oxide. Carbon 2007, 45, 1558-1565. [CrossRef]

39. Mattevi, C.; Eda, G.; Agnoli, S.; Miller, S.; Mkhoyan, K.A.; Celik, O.; Mastrogiovanni, D.; Granozzi, G.; Carfunkel, E.; Chhowalla, M. Evolution of electrical, chemical, and structural properties of transparent and conducting chemically derived graphene thin films. Adv. Funct. Mater. 2009, 19, 2577-2583.

40. Hontoria-Lucas, C.; López-Peinado, A.J.; de López-González, J.D.; Rojas-Cervantes, M.L.; Martín-Aranda, R.M. Study of oxygen-containing groups in a series of graphite oxides: Physical and chemical characterization. Carbon 1995, 33, 1585-1592. [CrossRef]

41. Jeong, H.K.; Yun, P.L.; Lahaye, R.J.W.E.; Park, M.H.; Kay, H.A.; Ick, J.K.; Yang, C.W.; Chong, Y.P.; Ruoff, R.S.; Young, H.L. Evidence of graphitic AB stacking order of graphite oxides. J. Am. Chem. Soc. 2008, 130, 1362-1366. [CrossRef]

42. Wei, D.; Liu, Y.; Wang, Y.; Zhang, H.; Huang, L.; Yu, G. Synthesis of N-doped graphene by chemical vapor deposition and its electrical properties. Nano Lett. 2009, 9, 1752-1758. [CrossRef] [PubMed] 
43. Ewels, C.P.; Glerup, M. Nitrogen doping in carbon nanotubes. J. Nanosci. Nanotechnol. 2005, 5, 1345-1363. [CrossRef]

44. Dai, X.; Du, K.; Li, Z.; Sun, H.; Yang, Y.; Zhang, W.; Zhang, X. Enhanced hydrogen evolution reaction on few-layer MoS 2 nanosheets-coated functionalized carbon nanotubes. Int. J. Hydrog. Energy 2015, 40, 8877-8888. [CrossRef]

45. Papirer, E.; Lacroix, R.; Donnet, J.; Nanse, G.; Fioux, P. Xps Study of the Halogenation of Carbon Black-Part 1. Bromination. Carbon 1994, 32, 1341-1358. [CrossRef]

46. Fiedler, R.; Herzschuh, R. An XPS investigation of the effects of heat treatment on the chlorine surface chemistry of some lignites. Fuel 1993, 72, 1501-1505. [CrossRef]

47. Mukdasai, S.; Poosittisak, S.; Ngeontae, W.; Srijaranai, S. A highly sensitive electrochemical determination of L-tryptophan in the presence of ascorbic acid and uric acid using in situ addition of tetrabutylammonium bromide on the ß-cyclodextrin incorporated multi-walled carbon nanotubes modified electrode. Sens. Actuators B Chem. 2018, 272, 518-525. [CrossRef]

48. Dourado, A.H.B.; Pastrián, F.C.; De Torresi, S.I.C. The long and successful journey of electrochemically active amino acids. From fundamental adsorption studies to potential surface engineering tools. An. Acad. Bras. Cienc. 2018, 90, 607-630. [CrossRef]

49. Zhang, Y.; Waterhouse, G.I.N.; Xiang, Z.P.; Che, J.; Chen, C.; Sun, W. A highly sensitive electrochemical sensor containing nitrogen-doped ordered mesoporous carbon (NOMC) for voltammetric determination of L-tryptophan. Food Chem. 2020, 326, 126976. [CrossRef]

50. Ye, D.; Luo, L.; Ding, Y.; Liu, B.; Liu, X. Fabrication of $\mathrm{Co}_{3} \mathrm{O}_{4}$ nanoparticles-decorated graphene composite for determination of 1-tryptophan. Analyst 2012, 137, 2840-2845. [CrossRef] 